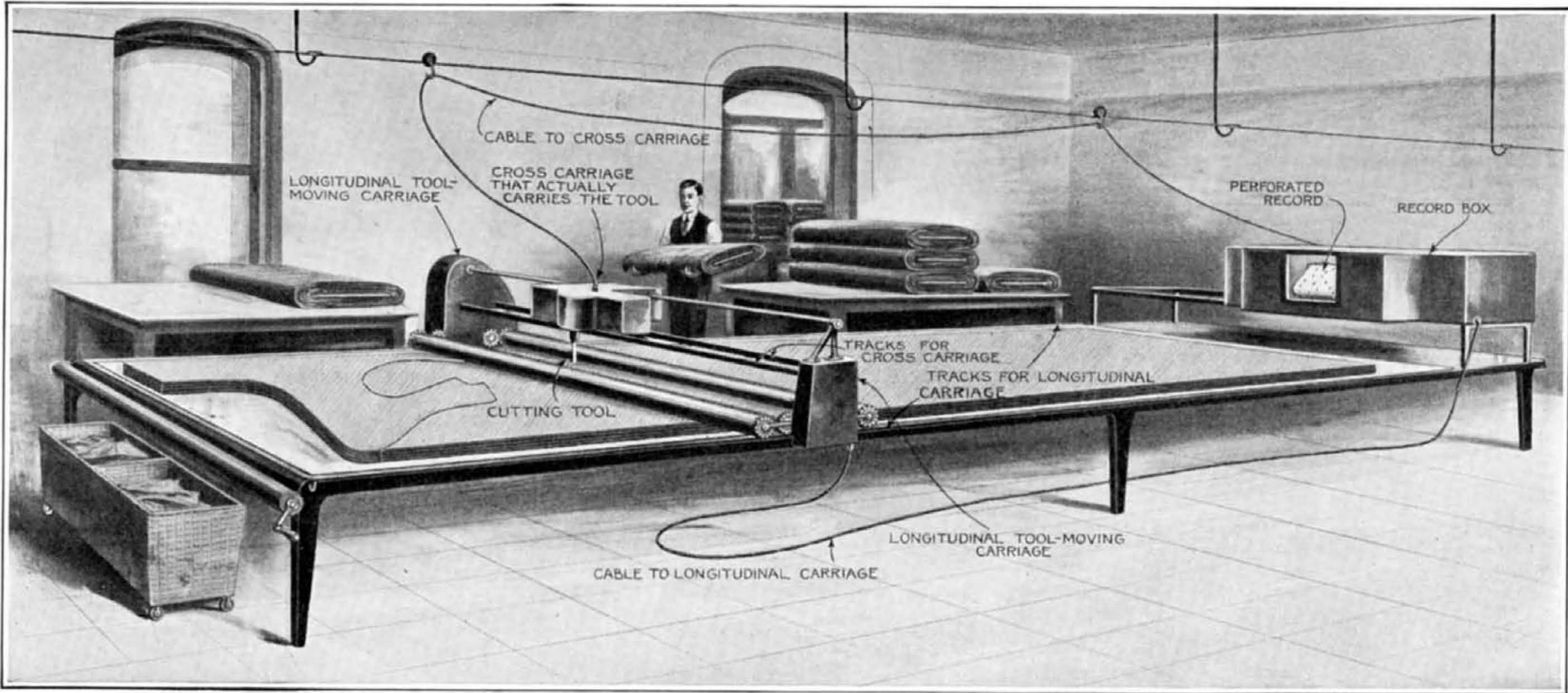

General diagram showing the application of paper-tape control to a machine for cutting cloth

\title{
When Perforated Paper Goes to Work
}

\section{How Strips of Paper Can Endow Inanimate Machines with Brains of Their Own \\ By Emanuel Scheyer}

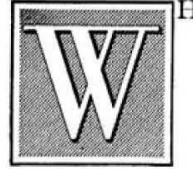

HER the subject of power comes up for discussion, attention is usually centered about the source of
the energy for our present and future requirements. This is all very well, for unless we know where our energy is coming from, we need indulge in but little worry as to what we are to do with it. But assuming that our wants are to be filled, in one way or another, it is rather in order to examine the question of what we are to do with all this power for which we are calling upon the coal mine, the oil well, the waterfall, perhaps the tides and the rays of the sun, and, we hope some day, the very atoms that go to make up all matter. When we get it, what are we to do with it?

It is perhaps superfluous to say that the chief use of power is to create motion. It is not quite so trite to point out that the motion we are talking about is in practically every instance rotation. Our power is needed to drive something 'round and 'round; having got this something to go 'round, the problem arises of how to make the rotating member do work for us. We are not concerned in this discussion with the use of the rotating something to generate light or heat, or to obtain locomotion.

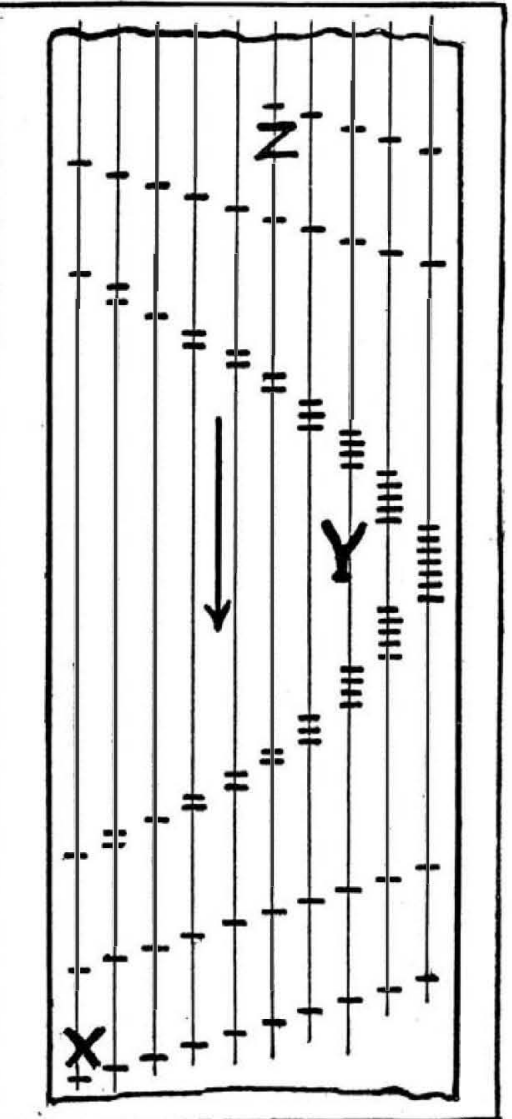

A specimen section of the per- that a few mysterious marks scratched on a bit of bark can act as the agency through which on man may direct another many miles distant, imposing his ever desire upon the actions of the other. To us today it is almost as inconceivable as this, what a part marked or perforated paper will play in the industry of the near future. The time is coming when workmen will be largely supplanted by such strips of paper when a walk through a factory will disclose hundreds of machines in operation with a mere handful of attendants fussing about. In some uncanny way, things will seem to be running themselves, very much as in the hoary story of the Chinaman, who, seeing for the first time a trolley car passing up the street, exclaimed: "No pushee, no pullee, no sabe how him goee?" A closer inspection of the machines would disclose how "him goee." Kinautograph mechanism would be attached to the various machines and rolls of perforated paper would be seen unwinding from some spools and on to others.

The kinautograph is a mechanism that will do for motion much the same thing that the phonograph does for sound. Just as in the phonograph, when you talk, a

hout voice which you can ested: our rotating power-producers are widely em- reproduce at will, just so in the kinautoployed to drive tools and machines for the creation of graph, if you put any given machine through manufacture articles.

Operating a machine, after all, amounts to applying one's guidance intelligently to the control of the motions of the machine's parts. The great bulk of the men employed in industrial occupations is concerne with doing just this thing. Therefore of equal importance in the conservation of human effort, as in the generation of power, is the devising of means for the automatic operation of machines.

To the unlettere savage, it seems hardly cred graph, if you put any given machine through its motions, a record is simultaneously made of these motions which will afterwards reproduce the original motions at will.

Once a record is made, the machine can be made to repeat its operations over and over again, and just as an automatic piano can be used to play an unlimited number of different musical compositions by using different records, just so the kinautograph can be used to perform unlimited sets of

different operations. The making of a record is very simple; the handles of the machine are grasped and the machine put through its motions, which causes a perforated paper record to be made of these motions. Upon reversing the process, the machine will automatically reperform these motions.

A typical example of a machine operated on the kinautograph principle is the kinautograph cloth-cutting machine. This machine will cut up fabrics into shapes ready to be sewn into collars, shirts, underwear, overalls and clothes. Not only is the cutting of every yard of the millions of yards of the fabrics entering into these garments one by hand now, but the pasteboard patterns must be arranged by hand on top of the pile of fabric and then marked out, after which the goods are cut With the kinautograph control, it is only necessary to spread the goods upon the table, insert a record into the control mechanism at one end, and start the machine, when an electric cutting tool will travel about the table by itself, just as if guided by hand, and cut up the goods into the shapes called for by the record. One attendant in charge of a group of these machines can turn out as much work as a dozen workmen can do now.

Our large drawing illustrates this application. The record box can be seen at the far end of the table. It contains a perforated record and other mechanism somewhat similar to that of automatic player pianos. Two electric cables lead from this box, one running on the floor under the table, and the other running overhead. Th e cables

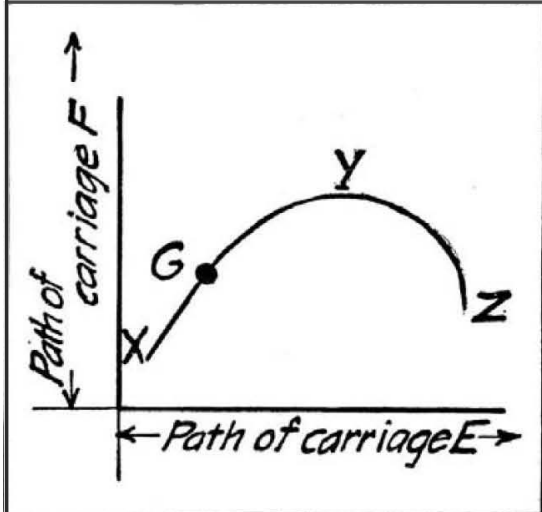

The path of the cutting tool as controlled by the tape-section shown at the left of the page. The points $X, Y$,
$Z$ in the two diagrams correspond le ad to tool-moving mechanisms, and the tool itself is shown. It consists of a thin blade of steel which is caused to jig up and down at a high rate of speed, and hence when moved $\mathrm{through}$ the fabric easily cuts its way. The tool-moving mechanism travels on tracks runing lengthwise, one on each of the long sides of the table. Traveling on cross-tracks th a t form a part of the toolmoving mechanism is a secondary carriage to which the tool is at tached. The tool-moving 
mechanism can travel back and forth on the cross-tracks across the width of the table. The combined motions of the tool-moving mechanisms enable the tool to be moved about so as to cut out any shapes desired, it being understood that the tool is always rapidly jigging up and down, as it is carried about. The motions of the tool-moving mechanisms are electrically controlled in accordance with the way the perforations follow each other on the record as it unwinds, the arrangement of these perforations being such that the tool. will be carried about to cut out the required shapes.

The motion of the cutting tool as it travels about the tal)le is split up into its

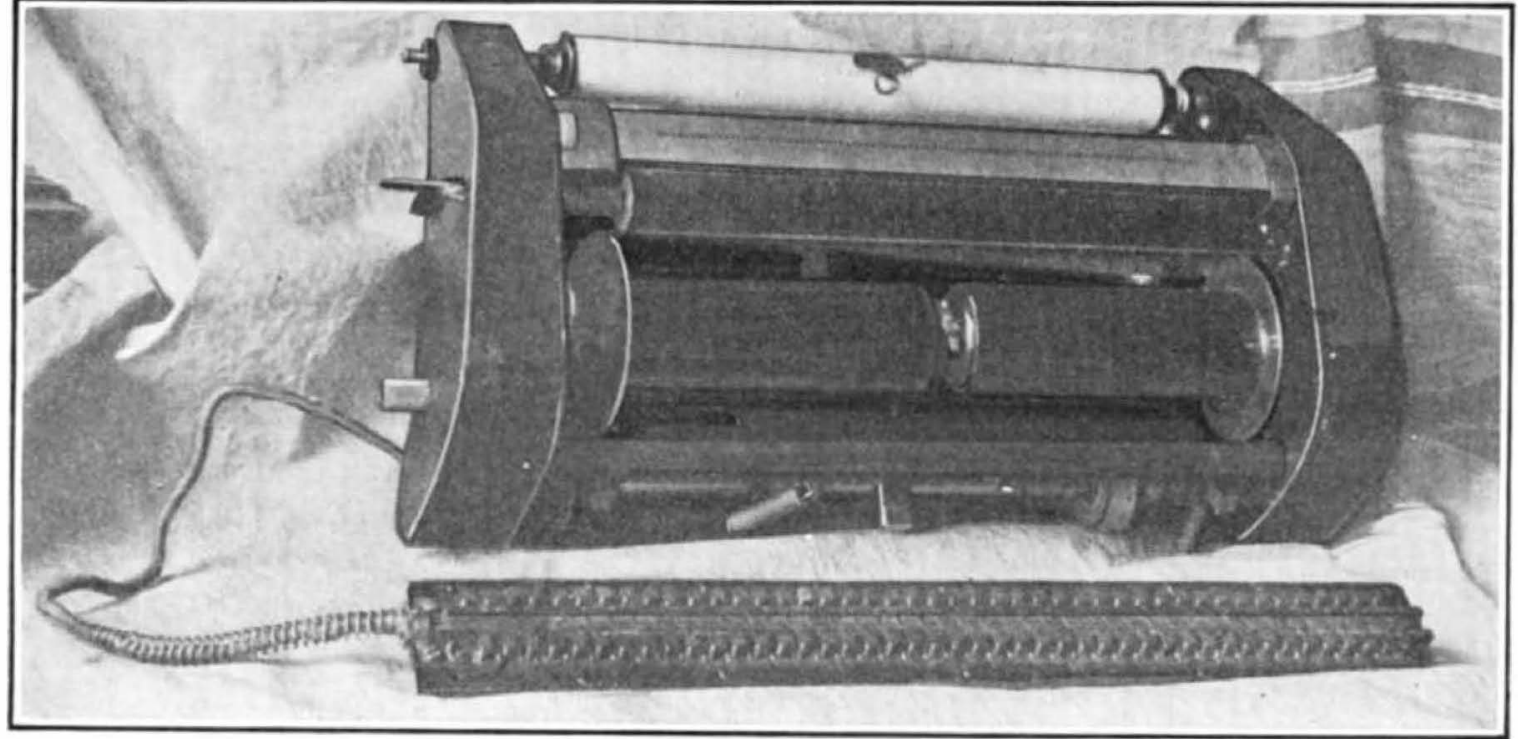

The tape-roll, blower tubes, electrical unit, etc., for the control of automatic machinery as described in components as it is possible to do with any moving body.

the text

The kinautograph, whose operation we have just described, is in fact a development of a previous invention of Jacquard, a countryman and contemporary of Napoleon. This device, named after its inventor, is frankly an intermittent affair, where the kinautograph is, within the limits imposed by the inescapable lag, continuous. The Jacquard has been used for many years in the control of machines where a step-by-step motion is sought. A good example is a particular type by one or more unit-elements acting at the same time the mechanism of each unit-element of a machine bein practically a duplicate of all the others.

This will be perhaps a little clearer

when it is explained just how the perforated paper acts upon the machine. In general terms it works through the opening and closing of electrical circuits; but this is again too general to be strictly informative. For better details reference must be made to the photograph in which the paper record is shown at the top, rolled about its spool. Directly beneath this will be noted a flat metal plate, pierced by a row of holes extending clear across it. The paper as it unrolls from its spool passes across this plate and therefore across the holes. The latter are really the ends of a series of tubes, which lead to a corresponding number of small air-cells covered over with thin of small air-cells covered over with thin
leather diaphragms. Each tube with its air-cell is connected to a suction pump. tubes cannot suck in any air when a solid part of the record is passing over them; but when a perforation in the record comes over the end of a tube, the ai rushes in through the tube to its corresponding cell and puffs out the diaphragm of the latter. Each cliapluragm is arranged to puff in and out against metal lic contacts which open and close an electric circuit, there being an air-cell, a diaphragm, a pair of contacts, and a tube for each of the binding posts shown on the board at the bottom of the picture. The lines of perforations in the record are arranged to slope to the right or to the left. As the perforations pass over the row of holes the air is sucked into succeeding holes, the uncovered holes from one instant to the next running to the right or to the left, depending on the slope of the lines of perforations passing over them. The tool-carrying mechanism is so designed that, as the circuits closed by the holes succeed each other to the right, it is moved to the right and when the circuits succeed each other to the left it is moved to the left, the speed of this motion depending on the slopes of the lines of the perforations. The nearer these lines approach the horizontal across the sheet the faster is the motion. At the point marked $\mathrm{Y}$ in the illustration of the record, where the line of perforations is vertical, the motion is zero. Response to the making and breaking of the circuits is naturally not instantaneous; but the mechanism is so arranged that the circuits are caused to interact one upon the other to compel the lag to be kept always within permissible margins of error for any class of work to be performed by a given machine.

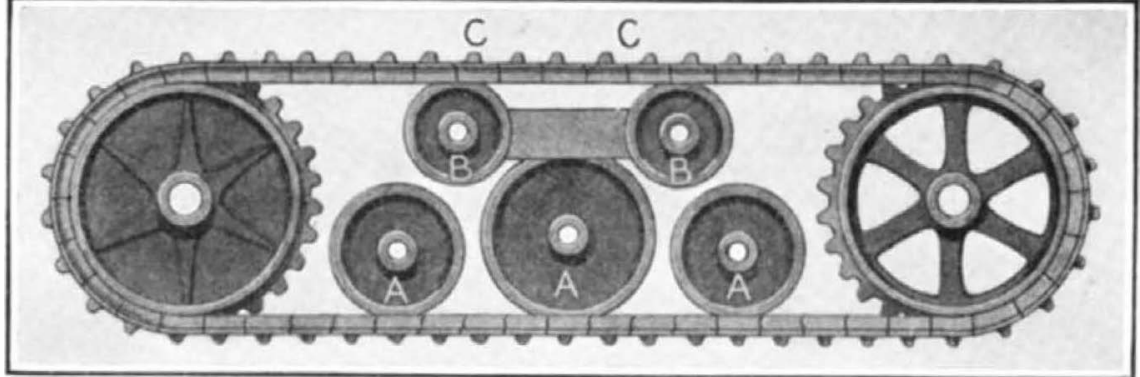

The rolls $A$ are necessary to support the tractor, and the rolls $B$ to support the track links $C$. The belt of the new tractor is so constructed that all such rolls and idlers are eliminated. It is

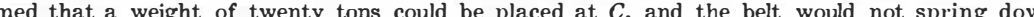

The feature of the track-layer which is done away with in the new model

f automatic embroidery machine, where the frame carrying the faloric is shifted from side to side between each stitch. The successive shifts are not through equal distances, nor is the cycle of repetition a short one; if either of these conditions were present it may be assumed that an ordinary cam control would be adequate. But the kinautograph is now driving similar embroidery machines, on which the fabric-carrying frame is kept in continuous motion, while the needles

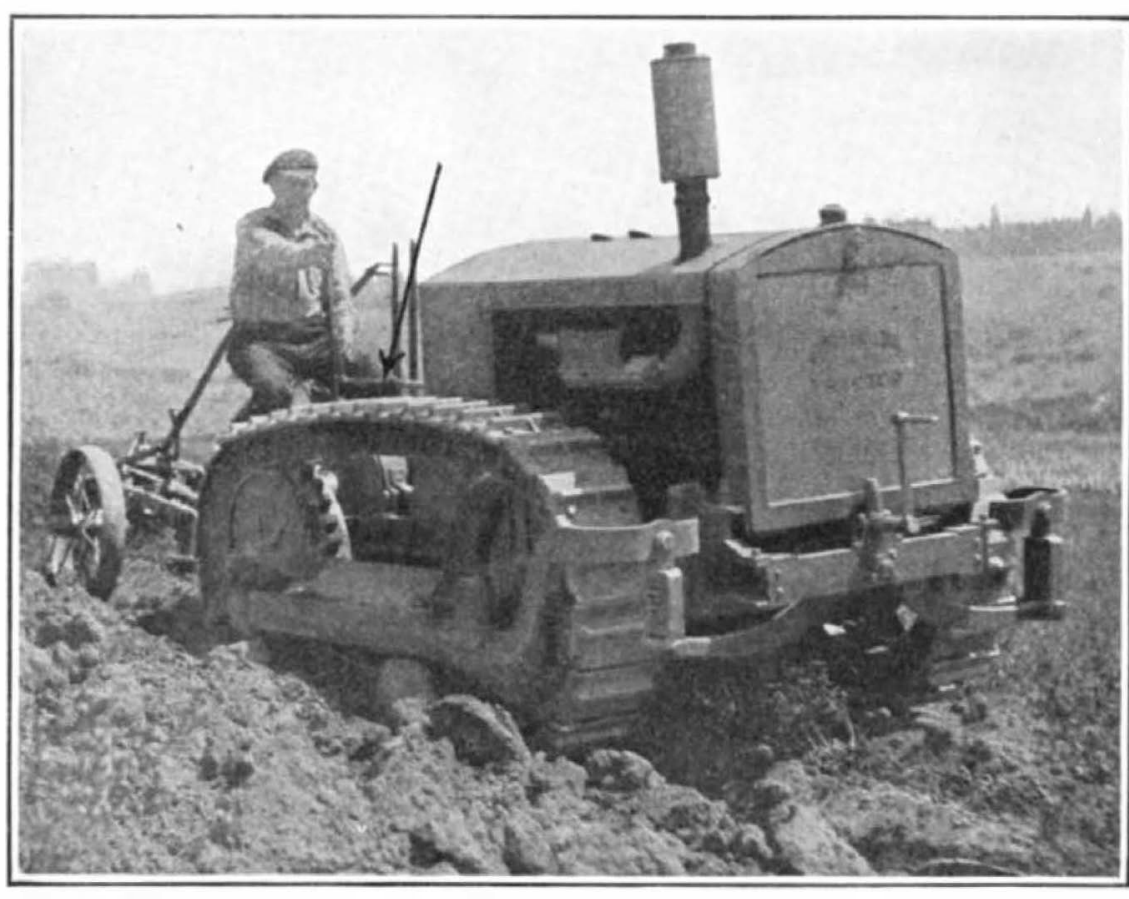

The rigid-belt track-layer in action. Note how the upper section of the track stands ripid are in constant operation
instead of being obliged to wait for the next stitch until the fabric is in the right position. The result of this advance is that practically the same embroidery machine on which the Jacquard works with a speed of 100 stitches per minute may be driven by the kinautograph at six times this speed.

The lathe, the most important tool used in the production of articles of metal, is ideally adapted to control by the Jacquard; even more so, perhaps, than by the kinautograph. Under ordinary procedure large and complicated pieces can be turned only on hand lathes. But by adding a Jacquard to the assembly, the paper record, instead of playing a waltz by Chopin, can just s easily turn out a steel car-axle. In this application ane holes in the record cause lathe stons to become perative at chosen times, and in addition actuate pneumatic cylinders for throwing in and out clutches which control the motions of the tool carriages against stops. The reason why the intermittent control Jacquard is so well suited the cutting tool must be moved only periodiaving been placed in the correct position for the next cut, and after the clutch has been thrown in to make the work rotate under the tool, nothing more in the way of control is necessary until the cut in question has been finished and another shift is in order. This plainly calls for intermittent rather than continuous control, and the Jacquard is apparently the logical means of securing it.

The possibilities of the kinautograph are far from adequately explored. Automatic dolls or manikins are marvelously adapted for control in this manner. What an interesting vaudeville stunt it would be to have two men dressed exactly alike, walk and turn about the stage doing their act, one being a ventriloquist, and have it all finally end by the real human being opening the other's coat and disclosing a perforated record and a lot of gearing. Since time immemorial men have endeavored to construct automata. Literature is full of stories of the (Continued on page 4.5 )

\section{The Rigid Track-Layer}

AEIV tractor just devised in San Francisco repreA sents an effort to get away from the necessity supporting the traction belt on machines of the track-layer type. "It has always been necessary, on these machines, to employ trucks, rolls or idle wheels to support the track and to take up the weight of the tractor itself at moments when only a small length of the track was in contact with the ground. In general terms, the means by which this necessity is avoided is through the provision of a belt that shall have a sufficiently rigid frame to distribute the load of the machine to the entire portion of the belt that is in a position to take any of it, rather than the concentration of this entire weight on a few links or joints at a time.

Thus the strain or pull is transmitted from link to link through heavy, widefaced lugs, acting through interposed pivot rings, All movement in the joints between the links is eliminated except when they leave the front sprocket and rise on the rear sprocket, the intermediate ground portion and the corresponding bridged portion above it being as rigid as a continuous bar. It is claimed that in thus supporting the load without track rollers an improved rolling effect is attained, with a greater percentage of applied power and the elimination of a great deal of the usual friction. 
offer announced on page 389, that we shall of the making of a picture-play film in which at an early date have our own first-hand the action involved dolls, and in which it experience with competent mediums to draw was necessary to pose each separate exposure upon for first-hand accounts of what hap- by moving the arms, legs, pens, and what does not happen, under the by hand. What was a job of many month exercise of the psychic powers. With be- in this way would have been absurdly simple ing the innocent bystander over whose befenceless form the combatants wage their strife we are done; we shall carry no more statements by persons who have not witWhatever of vicarious comment is to be made on psychic subjects through our pages we shall hereafter make ourselves, secur that it will then be made to our own satis faction, if to nobody's else.

City Street Dust and Infectious Diseases

I A very interesting article in Ecology of the Meteorological Laboratory, Mt. Vernon, N. Y., says: Most of the microorganisms found in street dust are harmless. of "suspects," still others are disease-bearing and deadly. The colon bacillus is almost universal where animals are used in street traffic. It is intestinal in origin and is abundant in the fecal discharges dropped on streets. As a part of the content of city street dust colon bacilli do not indicate the Kligler found the ratio of colon bacilli t other microorganisms somewhat greater than 1 to 1000 ; in one instance the number exceeded 60,000 per gram. Their number that in out-of-door dust. In medical science they are ordinarily regarded as harmless, but at times they are virulent.

The streptococcus is sometimes found in the horse-dung content of street dust; but the greater part is a product of human carelessness, due to the habit of promiscuous
corter carelessness, due to the habit of promiscuous expectoration. Streptococci in street dust, In themselves they are not regarded as harmIn themselves they are not regarded as harm-
ful. If they are of buccal origin, however ful. If they are of buccal origin, however, microorganisms that infect the mouth. Of the presence of tubercle bacilli in street dust there is no question. The re-
search of many years, covering practically search of many years, covering practically all the large cities of Europe and America, show that they are rarely absent. Although street dust moves normally from out of
doors to indoors, it is probable that tubercle bacilli accumulate indoors and are carried out of doors. The statistics gathered by
Winslow and Kligler show that, while only bout 5 per cent of the microorganisms in the dust of non-infected localities are tubercle bacilli, in infected localities the proportion is five times as great. Still further, the same authors find that, while in noninfected localities only 8 per cent of the animal deaths from all causes is due to tuberculosis, in infected localities abou granting that such values apply only to the localities in which the tests were made, the results show conclusively that infection from certain. So far as Europe and the United States are concerned, tuberculosis is not only pandemic; it is always with us; and although the death rate has been lowered, the total number of deaths therefrom has a reason therefore is not hard to find. Even if all other sources of infection be eliminated, street dust is competent to keep the disease with us. In the spread of microorganisms with us. In the spread of microorganisms first place to the "March gale." One might add that, if the velocity of an air current is doubled its capacity as a carrier of loose dust increases sixty-four-fold. Even with puts anything over the street sweeper's rattan broom. Either one is fully competent to
culosis.

When Perforated Paper Goes to Work

Continued from page 395)

with life and motion. In the well-known opera, "The Tales of Hoffman," one of the tales depicts as its central figure a life-sized automatic doll who plays the part of a young
lady. Of course the doll is a real lady who walks about with jerky movements and interrupted song, just as one would expect a mechanical contrivance to act, even to getting out of order and almost falling over. The Scientific AMERICAN of December stock several brands of soap to clean the
29, 1917, presented a most interesting story different classes of materials, or else make

possible for them to go through a little perA lasting say ten or fifteeen minutes. A machine which would automatically draw pictures should also prove an attraction in a show window. By using two carriages such as those of the cloth-cutting stead of a cloth-cutting tool, a machine can be constructed which will mysteriously draw pictures while the open-mouthed mob is looking on. Not only can pictures be drawn, how very simple the whole thing is, the how very simple the whole thing is, the
crowd can see words written which will tell them all about the thing advertised. A recrd of a few hundred feet could keep the achine going for hours. the phonograph in time with the motion picture film, producing talking pictures None of these has been wholly successful, established and understood that the acceptance of the talking film by the audience is somewhat doubtful; but passing this point over, the kinautograph offers a solution so projector and the phonograph is concerned. And there are many other arts in which the principle of the kinautograph can be applied. A beginning has been made in the control is thereby opened up for inventive endeavor.

The Dry-Cleaning and Dyeing Industry

Continued from page 396 )

solvent to run the average-sized up-to-date leaning plant.

Gasoline and benzol are used in cleaning in most cases very well defined, however, while in the case of gasoline and benzol tirely to their use as motor fuel. Motor gasoline and benzol were used by the cleaner
because no specifications for cleaning solvent because no specifications for cleaning solvent
were available. Motor gasoline will clean fabrics, but properties which are essential cleaning purposes. The light fractions are necessary to facilitate the starting of a mo-
or; but when present in a cleaning solvent, these mean loss because they evaporate the ractions of motor gasoline are objectionable because that part of the solvent is hard to remove from fabrics and imparts an objecwhich are not objectionable when used in limited quantities in motor fuel, are troublesome in cleaning solvent because it is diff-
cult to remove the imparted foreign odor. tions for cleaners' naphtha were prepared. An nvestigation of the

When specifications for a satisfactory solvent had been determined, it was another problem to ascertain the most practical and economical way to recover the solvent after it had been used for cleaning purposes. Used solvent contains soap, water, and finely di vided solid matter. For the most part these pubstances exist in colloidal state, and the
problem of recovering the solvent by chemiproblem of recovering the solvent by chemichemistry. Much work has been done on this problem and some promising results have been obtained. It must, however, be considered that solvent can be recovered by distillation in an efficient still for a fraction tillation in an efficient still for a fraction demands upon any chemical treatment that ay be proposed.

Another subject in which the cleaner is re on the market numerous brands, for the etergent properties of each of which there re made more or less elaborate claims. No ne brand combines very many desirable properties; hence a cleaner must have in

\section{Reminder of Rapid Standards}

You may stand at the workman's side, urging speed. Or you may put a counter beside him - urging speed quite as effectively. For the counter on his machine tells the operator how he's "making out" as surely as the boss could. It records his output and indicates his task with perfect accuracy-if it's a

Many attempts have been made to operate hemistry of water for specific industries is A study to determine the most practica

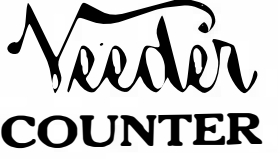

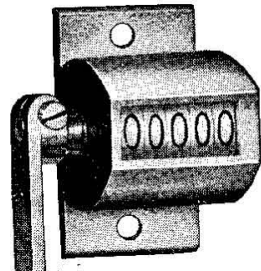

This small Rotary Ratchet Counter (No. 6) counts reciprocating movements of the lever, as required machines. When the lever is moved
through an angle of 40 to 60 degrees, the counnter registers one. A complete revo-
lution of the lever registers ten. This requirements, simplyy by regulating the (Cut nearly full-size)

There's a Veeder Counter for every machine where greater production should be expected. You'll find what you want in the (free) Veeder booklet - with full guidance in determining the counter to use.

\section{The Veeder Mfg. Co., 18 Sargant St.}

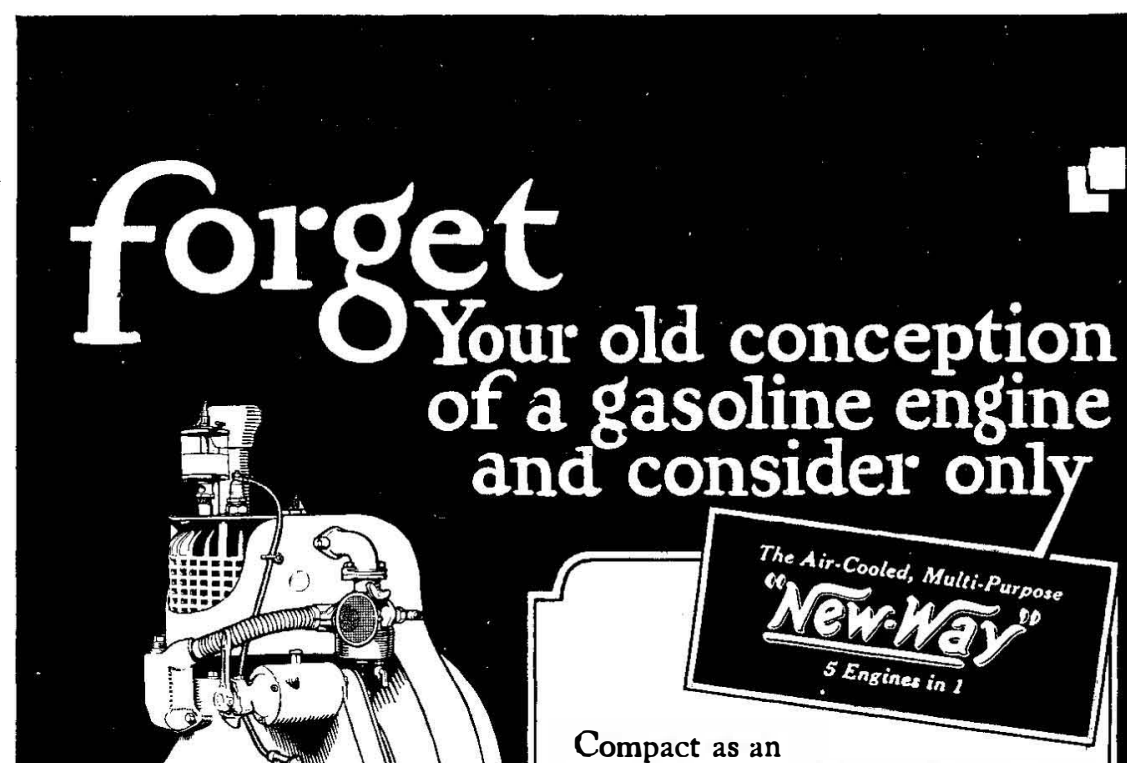

electric motor - flexible, dependable and light in weight. Especially designed to operate portable machinery, semi-portable, traction and stationary.

Operates by direct power or generator electric-motor driven units and tools in remote places.

Manufacturers and Engineers The "New Way" Engine in connec an important factor in their success.
Our engineering staff has had wide experience in the application of power to machinery of all kinds, and will be glad to help you.

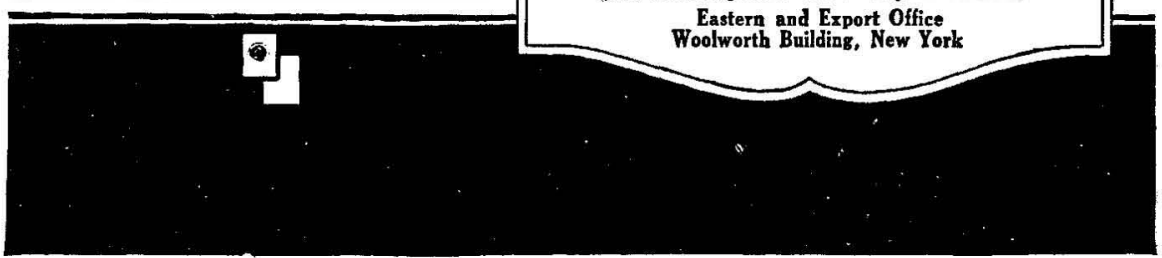

Variable control, 2 to 5 horse power.

Write for Circular C-20 THE NEW-WAY. MOTOR COMPAM tion with outfits of all kinds has proven Weight, ready to mount on any equip- 